\begin{tabular}{|c|c|c|}
\hline $\begin{array}{l}\text { PUCRS } \\
\text { PUC. }\end{array}$ & $\begin{array}{l}\text { ESCOLA DE } \\
\text { HUMANIDADES }\end{array}$ & $\begin{array}{l}\text { Revista Digital do Programa de Pós-Graduação em Letras da PUCRS } \\
\text { Letrônica, Porto Alegre, v. 13, n. 2, p. 1-14, abr.-jun. } 2020 \\
\text { e-ISSN: } 1984-4301\end{array}$ \\
\hline de) $\mathrm{http}: / / \mathrm{dx}$ & $\mathrm{org} / 10.15448 / 1984-4301.2020 .2 .35975$ & \\
\hline
\end{tabular}

\title{
(Diz)positivo para matar: uma análise sobre o discurso de ódio no Brasil contemporâneo
}

\author{
Device to kill: an analysis of the hate discourse in contemporary Brazil
}

\section{Marcelo Vinicius Costa \\ Amorim $^{1}$ \\ orcid.org/0000-0001-8916-7779 \\ m.viniciuh@gmail.com}

\section{Antônio Fernandes \\ Júnior ${ }^{1}$}

orcid.org/0000-0002-4969-0407

tonyfer@uol.com.br

toniferjr@gmail.com

Publicado em: 13 ago. 2020

\begin{abstract}
Resumo: O presente artigo consiste em uma análise de enunciados, mobilizando o conceito de discurso pela perspectiva foucaultiana em conjunto com a releitura de Deleuze. Outrossim, buscamos um diálogo com as contribuições teóricas de Achille Mbembe e o conceito de necropolítica, para então endossar nossas discussões sobre os discursos de ódio e seus desdobramentos em nosso cotidiano. Por meio de uma seleção de publicações presente nas redes sociais, usamos o método arquegenealógico para possibilitar uma reflexão sobre questões concernentes à política e às relações humanas no cenário atual do Brasil. Operamos uma crítica a partir do discurso de ódio, que é vigente, merecendo, assim, devidas cautelas para se repensar os processos de subjetivação a ele correlatos. Palavras-chave: Enunciado. Foucault. Discurso. Ódio. Necropolitica.
\end{abstract}

Abstract: The present article consists of an analysis of statements, mobilizing the concept of discourse from the perspective of Foucault together of Deleuze's rereading. Besides that, we sought a dialogue with Achille Mbembe's theoretical contributions and the concept of necropolitics, to endorse our discussions about hate speech and its consequences in our daily lives. Through a selection of posts on social networks we use the archenealogical method to enable a reflection on issues concerning politics and human relations in the current scenario in Brazil. We operate a criticism from the current hate speech, deserving due caution to rethink the related processes of subjectivation.

Keywords: Statement. Foucault. Discourse. Hate. Necropolitic.

\section{Introdução}

"Quem deve enfrentar monstros deve permanecer atento para não se tornar também um monstro. Se olhares demasiado tempo dentro de um abismo, o abismo acabará por olhar dentro de ti".

(Nietzsche)

Neste trabalho analisamos alguns enunciados que circularam, e, ainda circulam na sociedade brasileira contemporânea, cuja caracteristica discursiva nos possibilita compreender traços de uma produção de subjetividade marcada pela violência contra grupos e/ou sujeitos considerados de esquerda. Mais especificamente, iremos problematizar um fenômeno que tem ganhado corpo dia após dia, gradativa visibilidade que ressoa nos comportamentos cotidianos, o que chamaremos de discurso de ódio. Uma conceituação para pensarmos esse discurso é proposta por Schäfer, Leivas e Santos (2015, p. 147), que, em uma análise sobre diferentes concepções, entendem o discurso de ódio como uma 
prática dirigida "a estigmatizar, escolher e marcar um inimigo, manter ou alterar um estado de coisas, baseando-se numa segregação. Para isso, entoa uma fala articulada, sedutora para um determinado grupo, que articula meios de opressão".

Lançamos uma hipótese de que é facilmente detectável a existência e a operacionalização desse discurso, bastando apenas uma rápida imersão nas redes sociais para que se possa defrontar com postagens e comentários de conteúdo agressivo, atentando contra alguma existência humana especifica, que, por sua vez, apresentam alguma conexão com o que poderemos relacionar com a movimentação do cenário político. Para o pesquisador Jessé Souza (2019), a agressividade compõe parte dos discursos em nosso território brasileiro atual, e torna perceptivel a intima relação com um processo histórico em que se efetivou, ao mirar o desenvolvimento de uma dominação simbólica específica. Trata-se de um estratagema da elite para reavivar suas políticas de saque, ${ }^{2}$ devidamente amparados por uma classe média acometida pelo poder midiático. $O$ autor demonstra, em seu estudo, como certa fração conservadora da classe média se engaja em práticas que dão vazão ao ódio.

A questão ressaltada é que o ódio é conduzido, especificamente, para atingir a camada empobrecida, pois o interesse da classe média, em questão, não é apenas de cristalizar a sobreposição econômica existente em relação às classes ditas inferiores, mas a sua desenvoltura tem a ver com "se deliciar com o prazer sádico e covarde que antes era apanágio do senhor de escravos: o gozo da humilhação contra quem não tem defesa e precisa aturar calado a piada, o abuso, o insulto, a humilhação sob todas as formas" (SOUZA, 2019, p. 251). Nessa perspectiva, há um constructo de um bode expiatório para tornar cada vez mais inacessivel a compreensão dos processos políticos, distorcendo a percepção da realidade e, consequentemente, privilegiando reações truncadas, violentas e irracionais. Souza (2019) assevera que, dessa forma, o capitalismo financeiro age em conjunto com práticas discursivas neofascistas, minguando as possibilidades de vida, por intermédio de uma abertura, para que o racismo conquiste lugar cativo nas instituições e processos sociais, acompanhado também, pelo fluxo do ódio, indiscriminadamente. Embora as reflexões de Jessé Souza apresentem um bom aparato para pensarmos o cenário contemporâneo brasileiro, sua perspectiva está mais aparelhada a uma visão sociológica e, consequentemente, à consideração de intencionalidades elitistas em detrimento das outras classes, ou seja, ele traz mais exclusividade à sistemática do poder verticalizado.

Nosso propósito, com esta discussão, parte do legado filosófico de Michel Foucault (2008), especificamente, por nos possibilitar uma análise histórica que se furta do modelo de pesquisa que tenciona os pontos iniciais (mitos das origens ou fundadores etc.) como pedra fundamental de análise. $\mathrm{O}$ empreendimento foucaultiano evita o que chamamos de marcos inaugurais, que, pretensiosamente, tendem a explicar a realidade de hoje, em se tratando de causalidades univocas e fundamentais, em uma relação causa e efeito de acontecimentos linearizados. O modo de leitura da história, empreendido por Foucault, se marca pela descontinuidade e dispersão dos discursos efetivamente produzidos, a partir dos quais se pode fazer a conexão entre presente e passado, demonstrando como, por exemplo, os discursos de ódio produzidos na atualidade recuperam e/ou ressignificam práticas do passado. Nesse sentido, podemos afirmar que os discursos de ódio da atualidade estabelecem continuidade e descontinuidade com discursos antecedentes, contudo, não se dissociam de discursos futuros. O que os diferencia são as práticas discursivas contemporâneas com as quais/a partir das quais os discursos são produzidos e ganham visibilidade social. 
Neste cerne epistemológico, tomamos o enunciado como conceito chave para balizarmos as discussões, termo que Foucault (2008) irá propor para entendermos o discurso, não como uma fala, ou texto, mas um tecido, em que o enunciado se encontrará em algum ponto distinto. Portanto, é nessa maneira de compreender a circulação dos diferentes enunciados, bem como as suas filiações discursivas, que poderemos efetuar uma problematização do dito e do não dito, nos munindo de possibilidades para a construção de uma crítica ao nosso tempo presente, e seus modos de subjetivação, naquilo que diz respeito aos discursos de ódio, dentro dessa racionalidade histórica específica. Como parte da metodologia, nossa análise fundamenta-se em publicações selecionadas de material disposto nas mídias sociais, que compõem uma família de enunciados de determinada formação discursiva, enunciados esses que têm circulado pelos mecanismos de interação dispostos na internet.

\section{Reflexões teóricas}

Os apontamentos de uma análise foucaultiana destoam das veredas estruturais, não se vinculando às práticas interpretativas, e é por isso que optamos, neste trabalho, pelo método arquegenealógico, já que essa estratégia de pesquisa se caracteriza por um percurso mais intimo de uma operação descritiva. A descrição do enunciado só pode ser executada na medida em que reivindicamos suas relações com o processo histórico, mas não só, é preciso adotar uma perspectiva atenta às relações de saber e de poder historicamente construidas. Para Deleuze a arqueologia de Foucault seria a constituição de uma superfície de inscrição que não necessariamente se encontra oposta a uma profundidade, mas é, de fato, antagônico às práticas interpretativas. "Precisamente em Foucault, a superficie torna-se essencialmente superfície de inscrição: é todo o tema do enunciado 'ao mesmo tempo não visivel e não oculto'" (DELEUZE, 2013, p. 113).

Nesse entendimento de leitura, não se busca o que está por "trás dos discursos" ou o seu "sentido oculto". Nossa orientação, nesse caso, aponta para vias diferentes, no afã de privilegiar uma reflexão a partir da superfície do que é dito ou efetivamente produzido. Como forma de problematizar a construção dos discursos de ódio, por exemplo, como foco desta análise, buscamos alguns enunciados que o compõem, pois os discursos se formam por meio de conjuntos de enunciados apoiados em um mesmo sistema de formação (formação discursiva), enredamse em práticas específicas, vinculados ao arquivo (a lei do que pode ser dito), dentro uma dada racionalidade histórica especíica. Metodologicamente, certas questões devem ser recuperadas para se pensar a análise discursiva, a exemplo, quando Foucault (2008) interroga sobre o porquê de um enunciado e não outro em seu lugar. Dessa maneira, indagamos: por que os discursos de ódio adquiriram tanta visibilidade na atualidade? Sobre quais sujeitos ou grupos sociais eles incidem?

Portanto, do ponto de vista teórico e metodológico, nosso estudo se pauta na noção de enunciado trazida por Foucault (2008), que consiste, portanto, na compreensão daquilo que foi efetivamente dito e será tomado como uma função que tem um sujeito (uma posição), um referencial, um suporte, uma data, um lugar, e adquire dimensão semiológica, pois pode incorporar distintas materialidades (verbal, visual, sonora etc.), não se restringindo apenas aos aspectos linguísticos. Essa condição semiológica do enunciado nos auxiliará no entendimento do conceito de dispositivo de poder, pois esse se encontra atravessado por práticas discursivas e não discursivas, a exigirem, do analista, uma conversão do olhar para apreendê-lo na descontinuidade de discursos que o constituem, sendo, por ele, produzidos concomitantemente. O domínio do enunciado se marca pela ideia de multiplicidade, pois envolve diferentes relações com outros enunciados, se constitui como espaço para distintas posições de sujeito, multiplicidade de registros, dentre outros. Por esse motivo, quando Michel Foucault se desloca do registro arqueológico para o genealógico, seu empreendimento analítico se 
amplia para a análise dos dispositivos de poder, cuja envergadura teórica se pauta pela análise de um conjunto heterogêneo de elementos (discursos, enunciados, tratados de lei, o dito e não dito etc.), que tem como finalidade responder a uma dada urgência histórica, ou demanda de um tempo (FOUCAULT, 2014a).

Se o enunciado é a unidade mínima de análise do discurso, e os dispositivos de poder envolvem, dentre vários elementos, a presença de enunciados e discursos, é lícito dizer que a função enunciativa se presta, também, como recurso metodológico para a nossa reflexão sobre os discursos de ódio na atualidade, a partir dos quais se pode localizar a emergência desses discursos, sua relação com outros que o antecederam (domínio de memória), o campo referencial e a materialidade que os caracterizam, olhando para os elementos linguisticos e imagéticos concretizados nas postagens escolhidas. Em seguida, nosso olhar se volta para o dispositivo, a partir do qual buscamos observar sua configuração no campo das relações de poder e as urgências históricas produzidas. O gesto de análise arquegenealógico faz esse batimento entre a descrição dos enunciados que compõem o discurso e os dispositivos de poder aos quais estão emaranhados. Afinal, como assevera Courtine (2013), os discursos são imanentes aos dispositivos e não há dispositivo sem discurso.

Do ponto de vista da linguagem, os discursos e dispositivos não são inteiramente linguísticos, pois o enunciado não pode ser fixado aos elementos constitutivos de uma frase, nem aos valores que regem as proposições, tampouco a um ato de linguagem. Foucault (2003, p. 9), no livro A verdade e as formas jurídicas, avança mais nessa questão, ao afirmar que, por um dado tempo, o discurso era visto, por estudiosos do campo da linguagem, "como um conjunto de fatos linguísticos ligados entre si por regras sintáticas de construção". O autor reitera o valor dessas pesquisas e delas se afasta com o objetivo de delimitar o seu campo de observação para o que ele denomina de "fatos de discurso", ou seja, o de observar o discurso, não exclusivamente sob o seu aspecto linguístico, mas como "jogos estratégicos, de ação e reação, de pergunta e de resposta, de dominação e de esquiva, como também de luta" (FOUCAULT, 2003, p. 9).

Decerto, convém recuperarmos alguns elementos do processo de construção do pensamento de Foucault, exatamente para que esteja mais nitida a estratégia que compõe o trabalho de uma arquegenealogia. Foucault toma como fonte o fazer genealógico de Nietzsche, de tal maneira que "se apropria e aplica como instrumento na análise do nosso presente, das nossas relações, da constituição dos nossos corpos e subjetividades" (PRADO FILHO, 2017, p. 312). Foucault (2008, p. 178) afirma que a "arqueologia procura desenhar configurações singulares", sendo versada em uma prática de análise histórica de possibilidades do saber. Dessa maneira, a genealogia pode ser entendida como uma análise de proveniências - lugar do corpo e tudo o que the pertence -, que tem a ver com os pontos em que o corpo se articula com a história, uma vez que é nele, o corpo, que podemos nos deparar com os vestígios do passado (CASTRO, 2009).

O que delineamos até aqui versa sobre outra forma de análise, que está, inclusive, concomitante com as regras de prudências deixadas por Michel Foucault, as quais devem dar conta das questões concernente ao Saber, ao Poder e seus efeitos como processos de subjetivação. Foucault (2008, p. 220) afirma que seu olhar para o Saber está estreitamente ligado à noção de prática discursiva, pois o Saber consiste em um "conjunto das condutas, das singularidades, dos desvios de que se pode falar" em cada discurso específico. Nessa definição, o filósofo ratifica que certos saberes existem insubordinados às ciências, pois o saber tem estrita dependência com as práticas discursivas. É certo que o "saber não está contido somente em demonstrações; pode estar também em ficções, reflexões, narrativas, regulamentos institucionais, decisões políticas" (FOUCAULT, 2008, p. 221). Já o Poder aparece, na filosofia foucaultiana, para tratar sempre de um objeto de luta política, visto que aponta para o conceito de Poder como exercício e não substância que se detém. Foucault (2014b) nos demonstra como os discursos formam um emaranhado a justificar certo exercício de poder. 
As lutas políticas mobilizam técnicas e discursos, elaborados em campos de saber especificos, que se desenvolvem sincronicamente ao exercicio do poder. É justamente nessa prática social que se coloca em funcionamento dispositivos que incidem nas massas, mais propriamente, nos corpos dos individuos.

Deleuze (2013) considera que a concepção de Saber, em Foucault, é de suma originalidade, e não se reduz à ideia de conhecimento, e de que Saber e Poder não se dissociam:

O Poder delineia uma segunda dimensão irredutivel à do Saber, embora ambos constituam mistos concretamente indivisiveis; mas saber é feito de formas, o Visivel, o Enunciável, em suma, o arquivo, enquanto o poder é feito de forças, as relações de forças, o diagrama (2013, p. 120).

É necessário pensar que, em um percurso arquegenealógico, as dimensões saber-poder cumprem protagonismo na análise. Essa proposta de descrição e de análise discursiva vem sendo adotada no campo dos estudos discursivos foucaultianos, ${ }^{3}$ e, por esse motivo, muitos pesquisadores usam a expressão "análise arquegenealógica de discursos", quando se referem a uma dada metodologia de reflexão, que envolve tanto a emergência de certos discursos, historicamente produzidos, quanto as relações de poder que os atravessam. Tal estratégia de abordagem discursiva nos apresenta determinadas posturas, e requer de nós, analistas dos discursos, um olhar atento às práticas discursivas e não discursivas, a partir das quais se pode refletir sobre as constituições dos sujeitos. Um critério importante é renunciar uma conceituação de discurso como fenômeno de expressão, que daria privilégio à noção de autoria, individuo senhor do que diz. Exatamente, no discurso, é que "buscaremos antes um campo de regularidade para diversas posições de subjetividade" (FOUCAULT, 2008, p. 61). Em diálogo com essas questões, Piovezani e Curcino (2017, p. 44) comentam que, nas propostas de Foucault:

\begin{abstract}
O enfoque, quando da abordagem do discurso, na fase arqueológica que se ocupava do saber. dizia respeito às condições de possibilidade e controle do dizer. Quando do emprego do dispositivo, na fase genealógica, o autor predominantemente focalizou o poder e as condições de possibilidade e controle não apenas do dizer como também do fazer, do ver, logo, do ser (grifo dos autores).
\end{abstract}

Com efeito, a concepção da ferramenta analítica arquegenealógica ganha perspectiva de uma articulação/interlocução de práticas distintas propostas pelo próprio movimento de Foucault ao longo da trajetória de seu pensamento/ obra. Ressaltamos que é necessário, para nosso estudo em curso, elencar a noção de dispositivo, balizando nossa reflexão sobre o emaranhado de linhas analisáveis. Dispositivo, sendo uma noção baseada em apontamentos de Foucault, mas que se desenvolverá, com certa especificidade, na filosofia deleuziana. Em seu texto, "O que é um dispositivo?", Deleuze (2016, p. 360) propõe pensar o conceito de dispositivo como "conjunto multilinear", de linhas constantemente rompidas e bifurcadas, linhas de natureza heterogêneas, mas sempre correlatas ao Saber, Poder e Subjetividade. Analisar o dispositivo por essa perspectiva, consiste, em parte, em analisar e desemaranhar suas linhas de visibilidade e enunciação, essas que se equivalem à questão do Saber, bem como analisar as linhas de força, relativas ao Poder. Dessa forma o dispositivo possui seu caráter móvel, pois funciona de acordo com o fluxo dos discursos na trama social, opera junto da imediaticidade do poder inerente às relações humanas. Caso se caracterize pelo seu teor de novidade, o dispositivo só pode existir como uma maquinaria que requer constante revisão de suas linhas, que não param de passar, de conectarem entre si, de se romperem, mas, sobretudo, o dispositivo produz subjetividade.

Para fins de discussão do objeto que elencamos, e que nos ajuda a identificar os teores que compõem um dispositivo especifico, faremos uso das contribuições de Achilie Mbembe (2017), autor de uma releitura das ideias foucaultianas

3 Referimo-nos ao grupo de trabalho (GT) "Estudos Discursivos Foucaultianos", criado em 2018, e vinculado à Associação Nacional de Pesquisas em Letras e Linguistica (ANPOLL). Para mais informações, acessar o link: http://anpoll.org.br/gt/estudos-discursivos-foucaultianos. 
concernentes à biopolítica, concebendo, a partir desse diálogo, uma reflexão por via dos termos:

\begin{abstract}
necropolítica e necropoder para explicar as várias maneiras pelas quais, em nosso mundo contemporâneo, armas de fogo são implantadas no interesse da destruição máxima de pessoas e da criação de 'mundos de morte', formas novas e únicas da existência social, nas quais vastas populações são submetidas a condições de vida que lhes conferem o status de 'mortos-vivos' (2017, p. 146).
\end{abstract}

Dadas tais considerações, nas páginas seguintes, apresentamos o material a ser analisado, referente à emergência do discurso de ódio, à medida que mobilizamos enunciados, em diferentes materialidades, para o exercício da análise do referido discurso, e dessa prática tão em voga na racionalidade histórica pela qual a nossa atualidade é constituida. O discurso de ódio se materializa em distintas publicações de redes sociais, cartazes de manifestações, textos de internet etc., e, de modo geral, seu manifesto se dá pela dispersão em enunciados que circulam por diferentes espaços sociais. Ora são agressivos do ponto vista linguístico, ora do ponto de vista visual, fazendo uso de montagens e fotomontagens, que têm em comum o objetivo de desqualificar ou estigmatizar um adversário ou grupo social a partir de determinadas finalidades. O material escolhido não é extenso, dadas as finalidades deste texto, mas não deixa de apresentar a suficiência adequada para identificarmos traços do discurso de ódio conforme indicado na primeira parte dessa discussão. As postagens selecionadas têm, como alvo principal, políticos de esquerda, ou de grupos que defendem pautas de segmentos minoritários. Pautas essas que se tornaram bastante corriqueiras, no cenário político brasileiro, especialmente em meados da década mais recente, 2010-2020, do século XXI

\section{Enunciado para assassinar}

Durante a campanha para a disputa de presidenciáveis, na corrida eleitoral brasileira do ano de 2018, o então candidato da sigla PSL, Jair
Messias Bolsonaro, discursa, diante do público, em cima de seu trio elétrico de campanha, no estado do Acre. Bolsonaro diz: "Vamos fuzilar a petralhada", ${ }^{4}$ enquanto simula um fuzil atirando, ao empunhar um tripé de câmeras cinematográficas. Em seguida o autor da frase dá continuidade à sua fala, propondo a morte e o banimento dos intitulados petistas do território nacional. O enunciado propõe uma união ("vamos") para um extermínio de certa classe política, via armas de fogo. Podemos acessar o enunciado pela via da materialidade, que, nesse caso, foi filmado e replicado na plataforma de compartilhamento de vídeos YouTube, configurando, aqui, o suporte. Enunciado esse que, em seu domínio de memória, está conectado a outros enunciados preexistentes, recuperando, então, discursos produzidos e veiculados durante a ditadura militar no Brasil (1964-1985), periodo em que, conforme as condições históricas especificas, favoreceu o surgimento de práticas aparelhadas ao regime, interseccionando a caça aos "inimigos" da nação. A Escola Superior de Guerra (ESG), o Serviço Nacional de Informações (SNI) e a Ordem Política e Social (DOPS) protagonizavam, por exemplo, a caça aos comunistas, aos inimigos internos e aos críticos do regime estabelecido. Certamente, compondo uma novidade como "estrutura de poder e de controle social", algo que "se materializou com a publicação do Ato Institucional No. 1" (PRIORI et al., 2012, p. 200). É por essa perspectiva que podemos afirmar que o candidato do PSL e seus seguidores, por outras vias, recuperam e ressignificam o discurso ditatorial na atualidade.

Na busca pelas condições que possibilitaram o surgimento de tal enunciado, cabe-nos questionar o porquê desse e não outro em seu lugar, além de fazer uma reflexão, tencionando alcançar o sujeito que enuncia, que, nesse caso, não tem a ver, necessariamente, com o autor da formulação, pois, segundo Foucault (2008, p. 107), é preciso pensar o sujeito como um "lugar determinado e vazio que pode ser efetivamente ocupado 
por individuos diferentes". Trata-se de posições de sujeito que não podem ser assumidas por qualquer individuo, mas apenas por aqueles que se identificam com dado posicionamento e o reconhece como verdadeiro, subjetivando-o.

Em 2016, o Brasil e o mundo veriam a então presidenta eleita pelo Partido dos Trabalhadores (PT), Dilma Rousseff, sofrer um golpe e ser deposta de seu cargo. Um golpe que só pôde ser concretizado a partir de certos conluios entre uma utilização obscena do poder judiciário e uma significativa produção de mentiras assinada por grandes corporações midiáticas (SOUZA, 2019). A partir desse acontecimento, podemos constatar que havia, em curso, uma paulatina construção da ideia de que o PT, e demais partidos de esquerda, seriam o mal a ser combatido, permitindo, então, que o Brasil retomasse seu bom eixo de progresso socioeconômico. Sobre isso, Sousa (2018, p. 63) aponta que:

a intolerância às diferenças, apontadas pela direita como construção das políticas de esquerda, se espalha como uma forma de garantia a seus seguidores de serem conduzidos e de se conduzirem a uma vida de perfeição, livre daquilo que julgam como perturbador ao olhar e, por isso, segura. Assim, o Brasil vai assistir a um espetáculo de ódio encenado em suas ruas e redes sociais. São investidas contra a população LGBT, mulheres, negros, indios, religiões não cristãs, usuários de drogas que ganham lugar em enunciados e em práticas de violência.

Nessa linha de raciocínio, vamos caracterizando as possibilidades do acontecimento do enunciado, uma vez que uma frase não pode ser dita a qualquer momento, portando quaisquer conteúdos, o enunciado como existência possui suas regras, obedece a existências de outros enunciados em sua margem, funciona por uma rede, o que Foucault (2008, p. 111) chamará de campo associado, pois forma uma trama complexa, em que "não há enunciado que, de uma forma ou de outra, não reatualize outros enunciados".

Assim, podemos citar um segundo enunciado, que, talvez, não coincidentemente, é de autoria de um dos filhos de Jair Bolsonaro. Referimo-nos a uma publicação no Twitter, na conta oficial de Eduardo Bolsonaro, na qual ostenta uma arma de fogo (pistola) em uma das mãos, ao passo que, em outra, segura uma placa com os dizeres: "Eu pacificamente vou te matar". 5 No texto que compõe o enunciado verbal, há um destaque, em letras garrafais e, em caixa alta, para os termos "EU" e "MATAR". Ainda, na composição desse enunciado, ao lado de Eduardo, há um segundo indivíduo (Arthur Moledo do Val), empunhando uma espécie de espingarda. Trata-se de um youtuber que viria a ser o segundo deputado estadual mais bem votado, pelo estado de São Paulo, nas eleições de 2018. ${ }^{6}$ A data da publicação/tweet do referido enunciado é de novembro de 2016. Embora todo enunciado tenha um suporte e uma data, sua materialidade não se resume a isso, mas tem a ver com seu "status de coisa ou de objeto, jamais definitivo, mas codificável, relativo e sempre suscetivel de ser novamente posto em questão" (FOUCAULT, 2008, p. 115). Nesse segundo enunciado, há um novo elemento no jogo discursivo característico, ou seja, um modo de matar que, ainda que contraditório, anda junto de um fazer pacífico. Matar, eliminar, executar, não por/com crueldade, mas de modo abrandado.

O Twitter, nos últimos anos, tem sido local privilegiado, em que parlamentares e outros tantos representantes do povo, continuamente, publicam suas posições políticas e opiniões a respeito de acontecimentos diversos. No ano de 2014, nessa mesma rede social, outro parlamentar viria a protagonizar mais impropérios contra um grupo específico, outro enunciado, átomo do discurso de ódio. É nessa oportunidade que um processo judicial se instaura:

O Ministério Público Federal promoveu denúncia contra o pastor e parlamentar Marco Feliciano por declarações que indicam preconceito e discriminação, além de incitar o ódio entre grupos. São manifestações especialmente direcionadas para a comunidade LGBT A principal declaração vinculada ao pastor evangélico foi inserida como mensagem em

\footnotetext{
Para acompanhar a postagem oficial, bem como os comentários respostas: https://twitter.com/bolsonarosp/status/794692957676929024. Acesso em: 29 maio 2019.

Segundo apuração do TSE: http://divulga.tse.jus.br/oficial/index.html. Acesso em: 29 maio 2019
} 
sua conta na rede social Twitter, com o seguinte conteúdo: 'A podridão dos sentimentos dos homoafetivos levam (sic) ao ódio, ao crime, a (sic) rejeição' (SCHÄFER; LEIVAS; SANTOS, 2015, p. 150)

Compreendemos que o discurso de ódio implantado corrobora uma rede discursiva que se imbrica em um dispositivo de violência ainda mais peculiar, que poderíamos chamar de dispositivo de morte. Será necessário identificar esse dispositivo específico, pois justifica entender que a filosofia foucaultiana, regularmente, aponta para a análise de dispositivos concretos, isso na afirmação de Deleuze (2016).

Um dispositivo concreto produz algo, seu conjunto heterogêneo funciona sobre o amparo, retroalimentado e atualizado por decorrências específicas, portanto, como sugere o nome dispositivo de morte, vemos seus resultados. Em 2018 a então vereadora do Partido Socialismo e Liberdade (PSOL), Marielle Franco, é executada, com vários disparos, na Região Central do Rio de Janeiro.7 Em um segundo acontecimento, agora, em 2019, um carro é alvejado por disparos de oficiais do exército, na zona oeste do Rio, e cerca de 80 projéteis atingem o veículo, ceifando a vida de Evaldo dos Santos Rosa. Esse evento ainda se desdobraria, tardiamente, em uma segunda morte, Luciano Macedo, o catador de materiais recicláveis que estava presente no local. ${ }^{8}$ Acontece que a lista de assassinatos é demasiadamente extensa, e, em muitos casos, o terror instaurado começa pela própria ação de agentes do Estado.

Sobre o fato do assassinato de Marielle, poderemos avaliar uma gama de enunciados que se encontram dispersos nessa rede discursiva do ódio, um conjunto de comentários das redes sociais, reunidos no trabalho de Gisele Beighelman (2019), intitulado Odiolândia:
Todo preto quando morre, agora é moda fazer midia. [...] Lugar de bandido é na vala. Já foi tarde. MULHER NEGRA, DEFENSORA DE BANDIDO KKKKK (2019, p. 17).

Quem é dos Direitos dos Manos tem que ir no mesmo caminho que ela: caixão (2019, p. 18).

Nos USA, até presidente leva bala. Vão chorar no colo do capeta (2019, p. 19).

A obra de Beighelman consiste em um projeto que se baseou em comentários oriundos de publicações em redes sociais, necessariamente, a respeito de três fatos relevantes, o assassinato de Marielle Franco, em 2018, a invasão da Cracolândia pela Polícia Militar, em 2017, e o desabamento do Edifício Wilton Paes de Almeida, em 2018. No referido trabalho, iremos constatar a coexistência de debilidade de políticas públicas e uma espécie de preconceito guiado por aspectos raciais, de gênero e de classe. Assim é considerada a recorrência nos comentários:

\section{A culpabilização das vítimas, o desejo de ver mesmos destinos trágicos expandidos a outras minorias, como migrantes nordestinos, gays e sem-terra, é recorrente. A demanda pela liberação do porte de armas, pela pena de morte e pela intervenção militar, repete-se como um mantra capaz de solucionar tudo (BEIGHELMAN, 2019, p. 5).}

Embora tenhamos feito uso de casos emblemáticos, é preciso considerar outros numerosos e significativos casos de morte/ assassinatos. Por exemplo, os feminicidios envolvendo mulheres negras crescem sistematicamente, ao passo que, com mulheres brancas, têm caído os números. Esse é o alerta que a pesquisadora Jackeline Aparecida Romio nos faz. ${ }^{9}$ Há uma guerra em curso, contra um público específico. Neste ponto, é válido recordar os apontamentos de Davis (2016), expondo como se deu um conjunto de esforços ao final do século XIX e início do século XX, quando a

\footnotetext{
7 Ver reportagem disponível em: https://g1.globo.com/rj/rio-de-janeiro/noticia/vereadora-do-psol-marielle-franco-e-morta-a-tiros-no-centro-do-rio.ghtml. Acesso em: 29 maio 2019.

8 Ver reportagem disponivel em: https://brasil.elpais.com/brasil/2019/o4/o8/politica/1554759819_257480.html; https://www.terra. com.br/noticias/brasil/cidades/morre-segunda-vitima-em-acao-do-exercito-que-fuzilou-carro-de-musico,cegdebd95631cab7b8db6363d41bc64730wzzgyg.html. Acesso em: 29 maio 2019.

9 Ver publicação disponivel em: https://Www2.camara.leg.br/camaranoticias/noticias/DIREITOS-HUMANOS/565155-FEMINICIDIO-CRESCE-ENTRE-MULHERES-NEGRAS-E-INDIGENAS-E-DIMINUI-ENTRE-BRANCAS,-APONTA-PESQUISADORA.htmL. AcesSO em: 29 maio 2019.
} 
sociedade norte-americana se empreendeu em demonizar e massacrar a população de negros, particularmente, no sul dos Estados Unidos.

Houve um esforço para construção da ideia de que os negros, naturalmente, possuíam traços de lascivos, portadores de inclinações a práticas hediondas, produzindo sentidos de verdade para os individuos daquela sociedade, na medida em que seria muito arriscado brancos manterem proximidade com a população negra, sob o risco de desmantelamento da unidade familiar tradicional da época, argumento este que justificou, por exemplo, várias execuções de supostos estupradores negros, em decorrência de julgamentos ilógicos.

Conforme entendemos que os enunciados fazem parte de uma estratégia maior, produtora de uma corporeidade, ou seja, de um desdobramento último de subjetivação, o discurso de ódio, e as práticas de poder, colaboram com a produção/permissão do surgimento de novos assassinos, uma vez que há uma circulação e uma acentuação do ódio como formações discursivas. Isso é contraditório, pois o próprio Código Penal condena a incitação pública de qualquer crime, também, traduzido por apologia à violência. ${ }^{10}$ É possivel fazer uma descrição a partir do que Foucault (2008) apresenta como a priori histórico, concernente às condições de realidade para os enunciados, considerando que o discurso, não necessariamente, "tem um sentido ou uma verdade, mas uma história" (2008, p. 144). O discurso de ódio funciona no entrecruzamento com discurso religioso. Em última instância, veremos enunciados que englobam e defendem a política de armamentos sob a égide do "cidadão de bem". Tornou-se comum, no cenário brasileiro, por exemplo, cristãos, evangélicos, em maior medida, simularem armas com as mãos, posarem para fotografias, exibirem cartazes apoiando as armas pela vida. A própria terminologia Cidadão de bem, ${ }^{11}$ fora o nome de um jornal do movimento Ku Klux Klan, um grupo racista que praticava violência contra negros, ao mesmo tempo em que se defendiam por argumentos pautados em versículos bíblicos e em nome da proteção das familias americanas.

A vereadora Marielle, o Músico Evaldo e as mulheres negras compartilham de certos caracteres que os situam como alvo da política de morte. Segundo Mbembe (2017, p. 128) as questões do colonialismo, as diferenças, o estrangeirismo, a raça, a etnia, são as marcas necessárias para o apelo e a emergência da construção de um inimigo, que, por vezes, é um inimigo ficcional. "Na economia do biopoder, a função do racismo é regular a distribuição de morte e tornar possivel as funções assassinas do Estado".

Souza (2019) entende que há uma mentalidade covarde pautada em um preconceito específico, um tipo de ódio que está devotado ao aspecto da raça, que sobreviveu por algumas gerações. É que, dentro de nosso histórico escravagista, a classe média incorpora o ofício do capataz, servindo à elite e subjugando todo o resto da sociedade.

Nessa perspectiva, atribuir a relação entre o assassinato de uma militante de esquerda e os enunciados que compõem nosso objeto de análise, sugere o que Mbembe (2017) aponta como coexistência de razão, em conjunto de práticas políticas, que faz operar um rico meio estratégico de governar, que pode incluir em si, como estratégia, a política do terror. A partir das reflexões desse autor, consideramos que, nos últimos anos, um conjunto de narrativas foi experimentado, e colocado em prática, para que os jogos de saber-poder viabilizassem subjetividades que, por sua vez, incorporam um pensamento, interpretando um grupo de filiação partidária especifica como justamente responsável pelo mal a ser destruído. Esse movimento de intensa produção discursiva configura um determinado diagnóstico. O manifesto de enunciados como "PT destruiu minha vida", e outros tantos, partilham ideias comuns. Com isso, veremos como as minorias (negros, mulheres, comunidade LGBTTQ)

10 Ver publicação disponivel em: https://jus.com.br/artigos/68521/incitacao-apologia-e-cultura-da-violencia. Acesso em: 29 maio 2019. 11 Ver publicação disponivel em: https://www.diariodocentrodomundo.com.br/essencial/cidadao-de-bem-era-o-nome-do-jornal-da-ku-klux-klan. Acesso em: 29 maio 2019 
acabam sendo demonizadas em um efeito de convergência, pois a narrativa de expurgo e extermínio, inscrita em enunciados cotidianos, torna-se corriqueira, e vai produzindo efeito no corpo social. Achille Mbembe afirma que há uma transformação contínua das maneiras de matar, de uma razão que extermina certos individuos, que, em outros tempos, eram ceifados em campos de concentração, guerras, mas que, agora, se constituem em outras vias, instaurando e disseminando o medo, confeccionando um inimigo ficcional, mas com pertinentes efeitos na realidade:

Por sua vez, a generalização da insegurança aprofundou a distinção social entre aqueles que têm armas e os que não têm ("lei de distribuição de armas"). Cada vez mais, a guerra não ocorre entre exércitos de dois Estados soberanos. Ela é travada por grupos armados que agem por trás da máscara do Estado contra os grupos armados que não têm Estado, mas que controlam territórios bastante distintos; ambos os lados têm como seus principais alvos as populações civis desarmadas ou organizadas como milicias (MBEMBE, 2017, p. 141).

Já, para nossa realidade brasileira, veremos que estamos diante de

microfascismos, que emergem disfarçados de resistências reativas aos grupos supostos como perigosos, justificando medidas violentas da justiça e da sociedade, que se coloca como do lado do bem e dos bons costumes, por se julgar cumpridora das leis de Deus e dos homens (SOUSA, 2018, p. 66).

O lugar de sujeito desses enunciados virulentos, que carregam o ódio e pregam a morte, é onde encontraremos aquelas figuras icones do patriarcado, homens, caucasianos, conservadores, que se fundam na fé, que, não raro, irão encontrar o reduto da salvação no discurso cristão e sua "defesa" cotidiana por via das armas de fogo.

Em um estudo realizado entre 2001 e 2007. pelo Instituto de Economia e Pesquisa Aplicada (BRASIL, 2012), constatou-se que houve uma queda de, pelo menos, $60 \%$ do número de homicidios no Estado de São Paulo, após a promulgação do Estatuto do Desarmamento. Ignorando tais apontamentos, já, em 2019, eleito presidente do Brasil, Bolsonaro assina decretos, viabilizando mais armamento para a população. Em declaração sobre tal decreto, o então presidente argumenta: ${ }^{12}$

\begin{abstract}
Esse nosso decreto não é um projeto de segurança pública. É, no nosso entendimento, algo até mais importante que isso. É um direito individual daquele que porventura queira ter uma arma de fogo ou buscar a posse de uma arma de fogo, seja um direito dele, obviamente respeitando e cumprindo alguns requisitos.
\end{abstract}

Em um significativo estudo sobre como/quanto os indivíduos podem se tornar maus, Zimbardo (2013) afirma que a maior motivação de um soldado para que consiga matar, consiste, não necessariamente, naquele que carrega sua arma com munição, mas que, além das circunstâncias objetivas, o indivíduo deve agregar ódio em seu projétil.

\begin{abstract}
A imagem de um inimigo temido ameaçando o bem-estar pessoal de alguém e a segurança nacional da sociedade encoraja mães e pais a enviar seus filhos para uma guerra que fortalecerá governos que, por sua vez, reorganizarão prioridades, transformando o fio do arado em espada de destruição.

É tudo produzido com palavras e imagens. Para citar um velho ditado da língua inglesa: 'paus e pedras podem lhe quebrar os ossos, mas palavras podem matá-lo'. O processo se inicia com a criação de noções estereotipadas do outro, percepções desumanizadas deste outro, o outro como um imprestável, o outro como todo-poderoso, demoníaco, como um monstro abstrato, como uma ameaça fundamental a nossos mais caros valores e crenças (2013, p. 31-32)
\end{abstract}

Já, para Mbembe (2017), se as pessoas não conseguirem provar seu valor e utilidade. estarão qualificadas como grupo alvo e, então, sumariamente destruídas, sem que isso ressoe em qualquer sentimento ou julgamento de que haja um assassinato em curso, trata-se de um exercício regularizado de violência. Um processo de higiene imprescindivel para melhoria contínua da sociedade.

Observamos que muitas práticas e discursos apontados até aqui cooperam com a produção

12 Ver reportagem sobre decreto liberando a compra de mais de 2 bilhões de munições. Disponivel em: https://www.bbc.com/portuguese/brasil-48391614. Acesso em: 30 maio 2019 
de certo tipo de subjetivação, na qual sujeitos se produzem, fabricados por discursos de ódio, para operar na realidade cotidiana em busca de relações de violência, o que interrompe, inclusive o que Foucault (2004) chamou de liberação do campo, pois a violência é o que inviabiliza novas relações de poder. As consequências disso seriam a esterilização e o empobrecimento do campo das relações humanas. É o que podemos chamar de "estado de violência", sendo, assim, classificado como uma não relação, lugar que não sustenta a existência de exercicio de poder, pois o seu fazer é fatalista à medida que não suporta quaisquer práticas de resistência.

Os enunciados descritos neste estudo nos mostram que as práticas de intolerância são atravessadas por discursos violentos e direcionados a dado segmento social, no caso aqui exposto, a grupos e segmentos identificados como pertencentes a uma orientação política nomeada "de esquerda". No campo da linguagem, há um conjunto de dizeres, marcados por ameaças de morte ("Vamos fuzilar a petralada"/ "Eu pacificamente vou te matar"), insultos e/ou xingamentos variados; no campo das práticas, violências físicas e, em certos casos, o assassinato do outro (Marielle Franco), do diferente ou do estranho que não se enquadra em um padrão de normalidade estabelecido, em outras palavras, não entra no nicho do que pode ser tolerado. Os enunciados que nos propusemos a analisar, embora não se tenha esgotado as reflexões sobre - compõem o que foi designado, no inicio do texto, como discurso de ódio. Ao agrupar um conjunto de enunciados dispersos em diferentes publicações, mas com uma regularidade temática e modos de dizer característicos, temos uma formação de um discurso e, como desdobramento, a produção de verdades na e pela história. No caso dos discursos de ódio estudados, vimos como essa prática discursiva estabelece uma divisão social marcada por oposições binárias e a produção de inimigos a serem eliminados.

Esses discursos integram um dispositivo de poder, marcado por discursos heterogêneos, publicados de forma dispersa nos espaços virtuais, e tem como meta a eliminação do outro, considerado como diferente, identificado como inimigo a ser exterminado. Foram produzidos em uma conjuntura histórica específica, marcados pelo avanço das pautas neoconservadoras insatisfeitas, no caso brasileiro, com o avanço das políticas implementadas pelo Partido dos Trabalhadores no campo social (cotas, direitos sociais, pautas identitárias etc.). A urgência histórica desse dispositivo está em eliminar e/ou estigmatizar os apoiadores de tal partido (artistas, movimentos sociais, instituições, dentre outros), com o objetivo de naturalizar um discurso que se tornou corrente em muitos espaços sociais, delimitado pela equação: ser de esquerda é sinônimo de ser bandido. Com essa tática, os discursos e certos dispositivos de poder aqui discutidos recuperam estratégias adotadas em distintos momentos da história do nosso Pais, ora de forma direta, ora as ressignificando nas práticas discursivas da atualidade, fazendo uso do binarismo como forma de estabelecer os heróis e os vilões, aqueles que merecem visibilidade social (os cidadãos de bem) e aos demais, isolamento, morte e prisão.

Neste sentido, o dispositivo concatenado com a economia do ódio faz cálculos incompativeis com a justiça social. Inventa, rende e fornece a obliteração dos pobres e não da pobreza, na medida em que não consegue produzir resoluções que extirpem o sofrimento humano.

O atual e não muito inovador esforço para produzir certos e errados, bons e maus, concilia com o aspecto do discurso binário, também recorrente em nossa sociedade ocidental; no discurso de ódio, há sempre um inimigo a ser destruido; há sempre esse outro, o diferente ou o estranho a ser odiado, justificadamente produzido via práticas discursivas, verdades sintetizadas no emaranhado deste dispositivo de fins deletérios. Tão logo esse inimigo saia de cena, surge a emergência da criação de um novo. A máquina binária é extremamente eloquente para acionar o comportamento fascista (DELEUZE; PARNET, 1998); é por meio do binarismo que nós, os viventes, somos ignorados para que 
outros fins sejam admitidos. De alguma forma, as questões binárias têm sido alimentadas por discursos de ódio e crescem com vigor para rechaçar uma pretensa sociedade aberta ao diálogo. O dispositivo de morte apresenta, dentre outros elementos, em sua linha de "dizibilidade", a noção da presença imediata de um inimigo a ser destruido, suas linhas de luz desenham o objeto a ser liquidado, faz-se ver a necessidade de matar.

\section{Considerações finais}

Foucault concebe uma ideia de poder muito diferente daquela recorrente até então, digamos, por teorias que utilizam a noção de poder para explicar uma perspectiva macro, que está pautada em uma concepção de verticalidade do exercicio de poder. Na filosofia foucaultiana, não encontramos a negação da existência desse modo de operacionalização do poder. Seguramente essa concepção se faz importante para entendermos os grandes grupos, evidenciando a opressão e a dominação. Nessa chave de leitura, o Estado, por exemplo, é representado como o opressor da população. Na perspectiva de Foucault (2004), o poder não é uma substância, mas um exercício, e está presente em todas as relações, desde que haja alguma partícula de resistência, aliás, a própria resistência é uma faceta intrinseca do poder, portanto, não se reduz à ideia de opressão/oprimido. Assim, o poder é positivo, e, em sua microfisica, ele produz algo, diferente da noção de um poder estritamente repressivo (FOUCAULT, 2014a).

Deleuze (2013, p. 126) dirá que "é precisamente o elemento informal que passa entre as formas de saber, ou por baixo delas. Por isso é dito microfisico. Ele é força, e relação de forças, não forma". Essa premissa não elimina a possibilidade de existência de jogos de forças verticais tal qual aponta a leitura marxista. A filosofia foucaultiana assinala, sobre a questão do poder, a inclusão de novas leituras possiveis, tratando de uma trama mais fina e uma complexidade de relações do tecido social, que tem a ver com os jogos de verdade, a circulação dos discursos e exercícios de poder cada vez mais sutis e praticamente imperceptiveis. É toda uma teia que inviabiliza a percepção consciente de que somos, o tempo todo, induzidos a certos comportamentos. Como relata Foucault (2014a, p. 346), "Vivemos em uma sociedade que, em grande parte, marcha 'ao compasso da verdade' - ou seja, que produz e faz circular discursos que funcionam como verdade". A partir dessa afirmação, vemos como o corpo social tramita, ao mesmo tempo em que é produzido no emaranhado de forças e enunciados que estão se digladiando, se atualizando entre as pelejas políticas.

Uma onda conservadora pela afirmação de uma identidade majoritária, secularizada, branca, heterocentrada, e outros traços afins, combinada com a produção de um inimigo como diferença, aquele que está prestes a abalar esse conforto identitário, o que pressupõe alguns alertas e riscos para essa engendrada supremacia. "Quando a ameaça de abalo das identidades é vivida como um perigo intolerável, para neutralizar os efeitos disruptores das diferenças e garantir a permanência das identidades vigentes, se é capaz de tudo, inclusive matar" (ROLNIK, 2015, p. 17).

Os anos de governo petista, que culminaram em um levante de pautas identitárias, buscando temáticas de inclusão e proteção à diversidade, bem como reconhecimento de individuos marginalizados, serviu como objeto para ponto de convergência de um ódio que vem sido alimentado há tempos. O esforço que consistiu em apenas uma pedra fundamental não se consumou em uma profunda transformação das estruturas e das relações, para que se colocasse em curso, efetivamente, dispositivos eficazes para a produção massiva de subjetividades progressivas de espectro guiado ao bem da coletividade "É a ausência de processos de aprendizado coletivo e de sua institucionalização social e política que explica nossa abissal e indiferença ao sofrimento" (SOUZA, 2019, p. 161)

A morte se faz presente, mas o assassinato visa aos pobres. O ódio tornou-se molécula estruturante para se exercer uma violência argumentada e, o alvo é o negro, a mulher, o público LGBTTQ, as minorias como um todo. Um ódio ativo diante de classes populares, ódio que ataca certos corpos 
e existências. É esse desfecho preocupante que nos sugere a ambicionar, cada vez mais, práticas de resistências, que possam alimentar e abonar novos discursos entusiasmados com as diferenças, com as pluralidades, materializando condições para afirmarmos mais cores, vozes e afetos que incluam os grupos desumanizados, marginalizados, tratados, até então, como escória. O ódio e a negação ergueram seus edifícios concretizados nas práticas sociais, para os quais a argamassa vem das betoneiras neofascistas, trajadas de uma revolução neoliberal recheada de promessas inatingiveis. Nesse empreendimento as questões raciais assumem papel de alta relevância, permitindo que os laços entre as pessoas estejam assegurados por uma lógica escravagista, um elo entre senhor detentor dos bens e os outros que devem a ele se submeter. Se "os senhores de escravo tinham poderes de vida e morte sobre seus filhos, e não era infrequente que mandassem um irmão matar o outro" (DUNKER, 2014, p. 32), estamos situados em uma sociedade na qual poucas mudanças se efetivaram secularmente.

O que fica, para nós, é a necessidade imediata de construir mecanismos de detecção sobre como temos sido administrados por certos exercícios de poder-saber, que culminam na produção de relações de crueldade, construção de verdades perversas e de processos que docilizam e escasseiam nossas potências de vida, tornando embaraçosas nossas práticas de resistência. São processos que, além de revigorar as mazelas já postas, produzem subjetividades marcadas pela presença do ódio, impactando, desfavoravelmente, qualquer projeto de sociedade mais justa, é a corrosão dos movimentos sociais legítimos. O discurso de ódio evidencia a secular aniquilação do negro e avança contra todas as pessoas em condições minoritárias. Produz o sentido de que não é mais possivel tolerar certas existências, sendo necessárias práticas para além do confronto de ideias. Essa é uma das facetas do dispositivo que, aqui, analisamos.

\section{Referências}

BEIGUELMAN, Giselle. Odiolândia. Mulheres na coleção MAR. [S.l: s.n.], 2019.

BORTOLI, Sergio Eduardo Rudge. Incitação, apologia e cultura da violência: realidades na política e na sociedade brasileiras. Jus, ago. 2018. Disponivel em: https://jus.com.br/artigos/68521/incitacao-apologia-e-cultura-da-violencia. Acesso em: 29 maio 2019.

BRASIL. Instituto de Economia e Pesquisa Aplicada (IPEA). Menos armas, menos crimes. Daniel Ricardo de Castro Cerqueira; João Manoel Pinho de Mello. Brasilia. IPEA, 2012. Disponivel em: http://www.ipea. gov.br/portal/images/stories/PDFs/TDs/td_1721. pdf. Acesso em: 28 maio 2019.

CARVALHO, Joaquim de. "Cidadão de bem" era o nome do jornal da Ku Klux Klan. Diário do Centro do Mundo, 6 maio 2017. Disponivel em: https://www. diariodocentrodomundo.com.br/essencial/cidadao-de-bem-era-o-nome-do-jornal-da-ku-klux-klan/. Acesso em: 29 maio 2019.

CASTRO, Edgardo. Vocabulário de Foucault - Um percurso pelos seus temas, conceitos e autores. Trad. De Ingrid Muller Xavier; revisão técnica Alfredo Veiga-Neto e Walter Omar Kohan. Belo Horizonte: Autêntica Editora, 2009

COURTINE, Jean-Jacques. Decifrar o corpo: pensar com Foucault. Trad. Francisco Morás. Petrópolis, RJ: Vozes, 2013

DAVIS, Angela. Mulheres, raça e classe. Trad. de Heci Regina Candiani. São Paulo: Boitempo, 2016.

DELEUZE, Gilles. Conversações. Trad. de Peter Pál Pelbart. 3. ed. São Paulo: Editora 34, 2013.

DELEUZE, Gilles. O que é um dispositivo? In: LAPOUJADE, David (org.). Dois regimes de loucos - textos e entrevistas (1975-1995). Trad. Guilherme Ivo; revisão técnica de Luiz B. L. Orlandi. São Paulo: Editora 34. 2016. p. 359-369.

DELEUZE, Gilles; PARNET, Claire. Diálogos. Trad. de Eloíza Araújo Ribeiro. São Paulo: Editora Escuta, 1998.

DUNKER, Christian Ingo Lenz. Intolerância e cordialidade nos modos de subjetivação no Brasil. In: FANTINI, João Angelo (org.). Raizes da intolerância. [S.l: s.n.], 2014

FOUCAULT, Michel. A arqueologia do saber. Trad. De Luiz Felipe Baeta Neves. 7. ed. Rio de Janeiro: Forense Universitária, 2008.

FOUCAULT, Michel. A verdade e as formas juridicas Trad. Roberto Machado, Eduardo J. Morais. 3. ed. Rio de Janeiro: NAU Editora, 2003.

FOUCAULT, Michel. A Ética do Cuidado de Si como Prática de Liberdade (1984). In: Manoel Barros da Motta (org.). Trad. Elisa Monteiro, Inês Autran Dourado Barbosa. Ditos e Escritos V: Ética, sexualidade e politica. Rio de Janeiro: Forense Universitário, 2004. p. 264-287 
FOUCAULT, Michel. Microfísica do poder. Organização, introdução e revisão técnica de Roberto Machado. 28. ed. Rio de Janeiro: Paz e Terra, 2014a.

FOUCAULT, Michel. Vigiar e punir: nascimento da prisão. Trad. de Raquel Ramalhete. 42. ed. Petrópolis, RJ: Vozes, 2014b.

GONÇALVES, João Ricardo et al. Vereadora do PSOL, Marielle Franco é morta a tiros na Região Central do Rio. G1, Rio de Janeiro, 14 mar. 2018. Disponivel em: https://g1.globo.com/rj/rio-de-janeiro/noticia/vereadora-do-psol-marielle-franco-e-morta-a-tiros-no-centro-do-rio.ghtml. Acesso em: 29 maio 2019.

HAJE, Lara. Feminicidio cresce entre mulheres negras e indigenas e diminui entre brancas. Portal Câmara Notícias, Brasília, 7 nov. 2018. Disponivel em https://www.camara.leg.br/noticias/547491-feminicidio-cresce-entre-mulheres-negras-e-indigenas-e-diminui-entre-brancas-aponta-pesquisadora/. Acesso em: 29 maio 2019.

MBEMBE, Achille. Necropolitica. Arte \& Ensaios, [S.L.], n. 32, mar. 2017. ISSN 2448-3338. Disponivel em: https://revistas.ufrj.br/index.php/ae/article/ view/8993. Acesso em: 28 maio 2019

NIETZSCHE, Friedrich. Além do bem e do mal. Trad. de Márcio Pugliesi. Curitiba: Editora Hemus, 2004.

OKUMURA, Renata. Morre $2^{\mathrm{a}}$ vitima de fuzilamento de 80 tiros do Exército. Terra, São Paulo, 18 abr. 2019. Disponivel em: https://www.terra.com.br/noticias/ brasil/cidades/morre-segunda-vitima-em-acao-do-exercito-que-fuzilou-carro-de-musico,cegdebd95631cab7b8db6363d41bc64730wzzgyg.html. Acesso em: 29 maio 2019.

PIOVEZANI, Carlos; CURCINO, Luzmara. Fazer, pensar, dizer e olhar: dispositivos de fala pública e de leitura da mídia. In: FERNANDES JÚNIOR, Antônio; SOUSA, Kátia Menezes de (org.). Dispositivos de poder em Foucault: práticas e discursos da atualidade. 2. ed. Catalão: Editora Letras do Cerrado, 2017. p. 37-54.

PRADO FILHO, Kleber. A genealogia como método histórico de análise de práticas e relações de poder. Revista de Ciências Humanas, Florianópolis, v. 51, n. 2, p. 311-327, dez. 2017. Disponivel em: https://periodicos.ufsc.br/index.php/revistacfh/article/view/ 2178-4582.2017v51n2p311. Acesso em: 28 maio 2019. https://doi.org/10.5007/2178-4582.2017V51n2p311

PRIORI, Angelo, et al. A Ditadura Militar e a violência contra os movimentos sociais, políticos e culturais. História do Paraná: séculos XIX e XX [online]. Maringá: Eduem, 2012. p. 199-213. Disponivel em: http://books.scielo.org/id/k4vrh/pdf/priori-9788576285878-15.pdf. Acesso em: 10 out. 2019. https://doi.org/10.7476/9788576285878.0015

ROLNIK, Suely. Ninguém é deleuziano. Buenos Aires/ Lisboa: Notaciones Abisales, 2015. Disponivel em: http://www.notacionesabisales.com/wp-content/uploads/2015/07/nadie-es-deleuziano-bilingue.pdf. Acesso em: 10 out. 2019
ROSSI, Amanda; MACHADO, Leandro. Com decreto de Bolsonaro, mais de 2 bilhões de munições podem ser compradas por brasileiros que já têm armas. BBC, São Paulo, 27 maio 2019. Disponivel em: https://www.bbc.com/portuguese/brasil-48391614. Acesso em: 30 maio 2019.

SCHÄFER, Gilberto; LEIVAS, Paulo Gilberto Cogo; SANTOS, Rodrigo Hamilton. Discurso de ódio: Da abordagem conceitual ao discurso parlamentar. Revista de Informação Legislativa, Brasília, a. 52 n. 207. jul./set. 2015. Disponivel em https://www12.senado. leg.br/ril/edicoes/52/207/ril_v52_n207_p143.pdf. Acesso em: 26 set. 2019.

SOUSA, Kátia Menezes de. A construção das verdades na condução das condutas dos brasileiros, a intolerância como forma de resistência e o precipitar dos acontecimentos discursivos. Cadernos Discursivos, Catalão-GO, v. 1 n 1, p. 56-76, 2018. Disponivel em: https://cadis_letras.catalao.ufg.br/ up/595/o/K\%C3\%A1tia_Menezes_.pdf. Acesso em: 29 maio 2019

SOUZA, Jessé. A elite do atraso. Rio de Janeiro: Estação Brasil, 2019.

ZIMBARDO, Philip. O efeito Lúcifer: como as pessoas tornam-se más. Trad. de Tiago Novaes Lima. 2. ed. Rio de Janeiro: Record, 2013.

\section{Marcelo Vinicius Costa Amorim}

Mestrando em Estudos da Linguagem pela Universidade Federal de Goiás-Regional Catalão/Universidade Federal de Catalão (UFG-RC/UFCat, Catalão, GO, Brasil). Bolsista CAPES. Graduado (Bacharelado e Licenciatura) em Psicologia pela Universidade Federal de Goiás - Regional Catalão (UFG- RC), Catalão, GO, Brasil.

\section{Antônio Fernandes Júnior}

Doutor em Letras pela Universidade Estadual Paulista "Júlio de Mesquita Filho" (UNESP/FCLAr, Araraquara, SP, Brasil). Docente na Graduação e Pós-Graduação em Letras na Universidade Federal de Goiás-Regional Catalão/Universidade Federal de Catalão-UFCat/em implantação (UFG-RC/UFCat) em Catalão, GO, Brasil.

\section{Endereço para correspondência}

Marcelo Vinicius Costa Amorim/ Antônio Fernandes Júnior

Universidade Federal de Goiás - Regional Catalão. (em transição, Universidade Federal de Catalão [UFCat])

Av. Dr. Lamartine Pinto de Avelar, 1120, Bloco E, sala 02 75704020

Catalão, GO, Brasil 